\title{
Surrogate rearing a keystone species to enhance population and ecosystem restoration
}

\author{
Karl A. Mayer, M. Tim Tinker, Teri E. Nicholson, Michael J. Murray \\ Andrew B. Johnson, Michelle M. Staedler \\ Jessica A. Fujil and Krle S. Van Houtan
}

\begin{abstract}
Translocation and rehabilitation programmes are critical tools for wildlife conservation. These methods achieve greater impact when integrated in a combined strategy for enhancing population or ecosystem restoration. During 2002-2016 we reared 37 orphaned southern sea otter Enhydra lutris nereis pups, using captive sea otters as surrogate mothers, then released them into a degraded coastal estuary. As a keystone species, observed increases in the local sea otter population unsurprisingly brought many ecosystem benefits. The role that surrogate-reared otters played in this success story, however, remained uncertain. To resolve this, we developed an individual-based model of the local population using surveyed individual fates (survival and reproduction) of surrogate-reared and wildcaptured otters, and modelled estimates of immigration. Estimates derived from a decade of population monitoring indicated that surrogate-reared and wild sea otters had similar reproductive and survival rates. This was true for males and females, across all ages (1-13 years) and locations evaluated. The model simulations indicated that reconstructed counts of the wild population are best explained by surrogate-reared otters combined with low levels of unassisted immigration. In addition, the model shows that $55 \%$ of observed population growth over this period is attributable to surrogate-reared otters and their wild progeny. Together, our results indicate that the integration of surrogacy methods and reintroduction of juvenile sea otters helped establish a biologically successful population and restore a once-impaired ecosystem.
\end{abstract}

Keywords Enhydra lutris nereis, individual-based models, population recovery, post-release, southern sea otter, surrogacy, survival, wildlife rehabilitation

Karl A. Mayer, Teri E. Nicholson ((D) orcid.org/0000-0002-9895-1458), Michael J. Murray, Andrew B. Johnson, Michelle M. Staedler, Jessica A. Fuji (Corresponding author, (D) orcid.org/0000-0003-4794-479X) and KYLE S. VAN HoutaN* (10 orcid.org/0000-0001-5725-1773) Monterey Bay Aquarium, 886 Cannery Row, Monterey, California 93940, USA. E-mail kmayer@mbayaq.org

M. Tim Tinker $\dagger$ (10 orcid.org/0000-0002-3314-839X) Department of Ecology and Evolutionary Biology, Long Marine Laboratory, University of California, Santa Cruz, USA

*Also at: Nicholas School of the Environment, Duke University, Durham, USA $\dagger$ Also at: U.S. Geological Survey, Western Ecological Research Center, Santa Cruz, USA

Received 17 February 2019. Revision requested 4 April 2019.

Accepted 10 April 2019. First published online 20 September 2019.
Supplementary material for this article is available at https://doi.org/10.1017/So030605319000346

\section{Introduction}

Wildlife conservation may involve management interventions to achieve both population and ecosystem goals. One type of conservation intervention, translocation, has become an important tool for rebuilding the abundance, expanding the geographical range, and improving the genetic diversity of wild populations (Griffith et al., 1989; Pimm et al., 2006; Seddon et al., 2007; Van Houtan et al., 2009; Batson et al., 2015). For critically-reduced, dispersallimited, or highly fragmented populations, translocation is among the most effective methods to rebuild populations (Sarrazin \& Barbault, 1996; Fischer \& Lindenmayer, 2000). In addition to recovering populations, translocation may also help to restore degraded ecosystems. Reestablishing key grazers or top predators, for example, can restore important ecological functions that are critical to ecosystem health (Berger et al., 2001; Beschta \& Ripple, 2009; Seddon et al., 2014).

Although the conservation benefits of translocation are often clear, its implementation may be challenging. Successfully capturing and moving wild individuals may involve practical and logistical hurdles, particularly if the source populations are severely depleted (Miller et al., 1999). Translocation programmes may also be complicated by political, socioeconomic and legal conflicts (Loomis, 2006; Massei et al., 2010). The success of such efforts may further be constrained by the behaviour of the species themselves, as relocated animals may behave unpredictably and ultimately not assimilate within their targeted sites (Ruth et al., 1998; Carswell et al., 2015). Successful translocation programmes must overcome such challenges.

In addition to translocation, rescue and rehabilitation programmes can be useful in wildlife conservation efforts. At the most basic level, such programmes can collect pivotal data to inform management about vulnerable demographics and hazards populations encounter that lead to stranding (Van Houtan et al., 2010; Nicholson et al., 2018). Beyond this, the temporary captive care and rehabilitation of stranded individuals has been a part of species conservation and reintroduction efforts for a number of species categorized as Threatened 

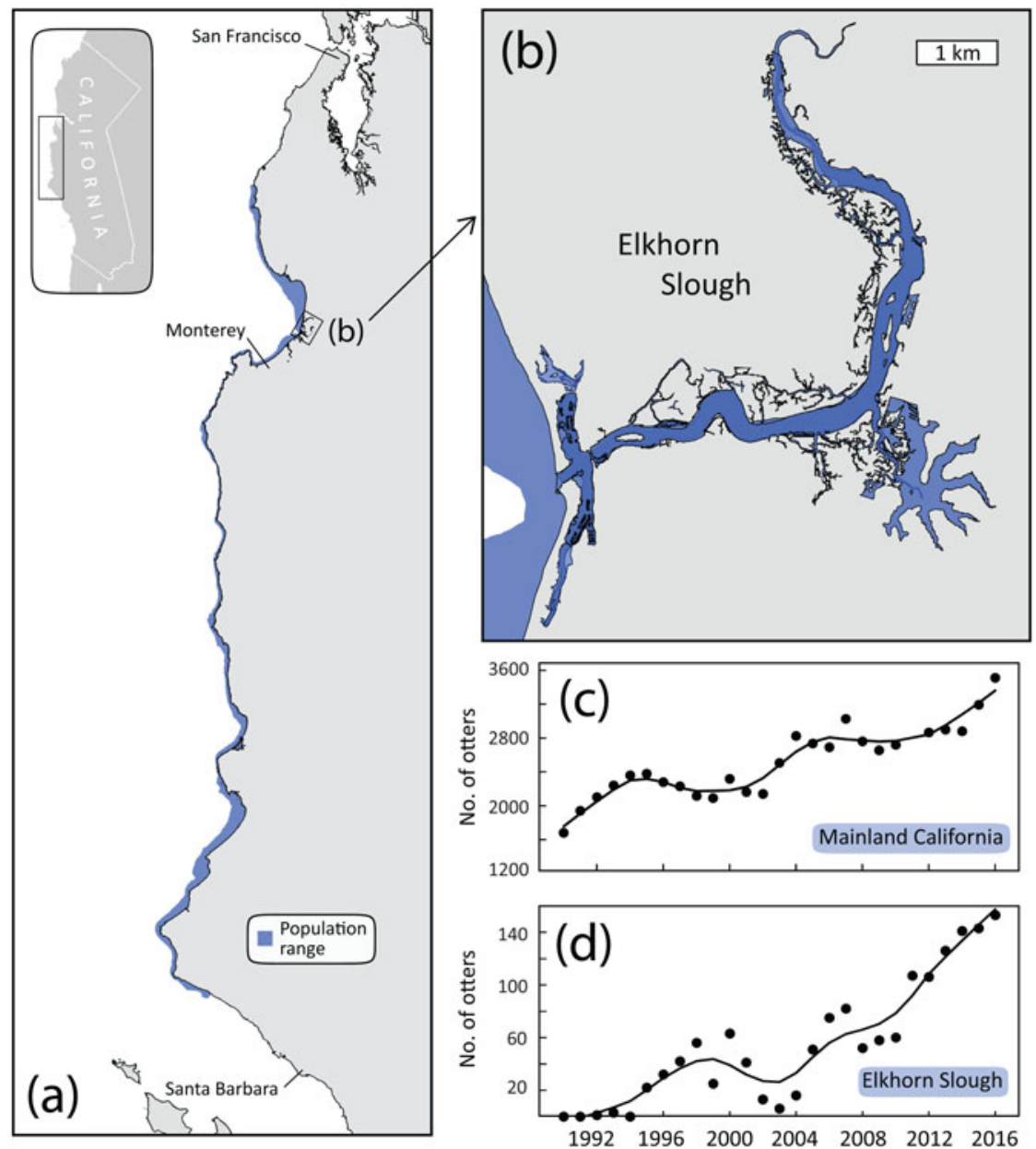

FIg. 1 Current range and population abundance of southern sea otters Enhydra lutris nereis through time. (a) Full extent of the mainland California population range, stretching from Pigeon Point in the north to Point Conception in the south, including habitats of $\mathrm{o}-30 \mathrm{~m}$ depth. (b) Extent of the Elkhorn Slough, the largest estuarine ecosystem within the current population range, where the study occurred. Population counts of sea otters (c) throughout their California range and (d) in the Elkhorn Slough during 19902016. Although both trends increase over time, the rise of the Elkhorn Slough group is by comparison more rapid, especially since 2002 , from when surrogate-reared otters were released into that ecosystem. or Endangered under the Endangered Species Act, such as Hawaiian monk seals Monachus schauinslandi and manatees Trichechus manatus (Gilmartin et al., 2011; Norris, 2011; Adimey et al., 2016). Although such programmes have faced numerous obstacles and criticisms, often these stem from a systematic lack of data on post-release survival, or formal analysis of the population and ecosystem impacts of releasing rehabilitated individuals (Guy et al., 2013).

In this study we focus on a specific type of translocation, reintroduction, which involves moving animals within the species' historical range for the purpose of enhancing and expanding the population (Kleiman et al., 1994). Southern sea otters are currently categorized as Threatened under the Endangered Species Act (USFWS, 2003), and their distribution is limited to $500 \mathrm{~km}$ of the central California coastline (Fig. 1; Tinker \& Hatfield, 2016). The population remains concentrated in the geographical center of its distribution, where densities have been historically high, and this region is believed to be at carrying capacity (Laidre et al., 2001; Tinker et al., 2008). Beyond this core area, a number of threats appear to be limiting the population from naturally expanding into unoccupied portions of its historical range and thus impeding greater recovery (Tinker et al.,
2008; Lafferty \& Tinker, 2014; Tinker \& Hatfield, 2016; Nicholson et al., 2018).

Sea otters have long been recognized as a keystone species throughout the North Pacific (Estes \& Palmisano, 1974; Estes \& Duggins, 1995). After being hunted to nearextinction (Kenyon, 1969), their gradual recovery in a variety of near shore habitats (including rocky subtidal areas, soft-sediment communities, and seagrass dominated estuaries) has resulted in trophic upgrades such as increased kelp abundance and improved sea grass health (Estes et al., 2011; Hughes et al., 2013). Thus, a proactive management approach that targets reintroduction of sea otters to historical areas would benefit population recovery and ecosystem restoration.

To circumvent many of the hurdles for translocation and rehabilitation programmes, we propose that, in certain cases, stranded or orphaned juvenile animals can be reared and utilized as a source population for reintroductions, in lieu of captured wild animals. Most orphaned sea otter pups strand with acute symptoms of maternal separation (i.e. dehydration, hypothermia and/or hypoglycemia), rather than severe injury or chronic disease. Therefore, they may be restored to normal health with basic medical 

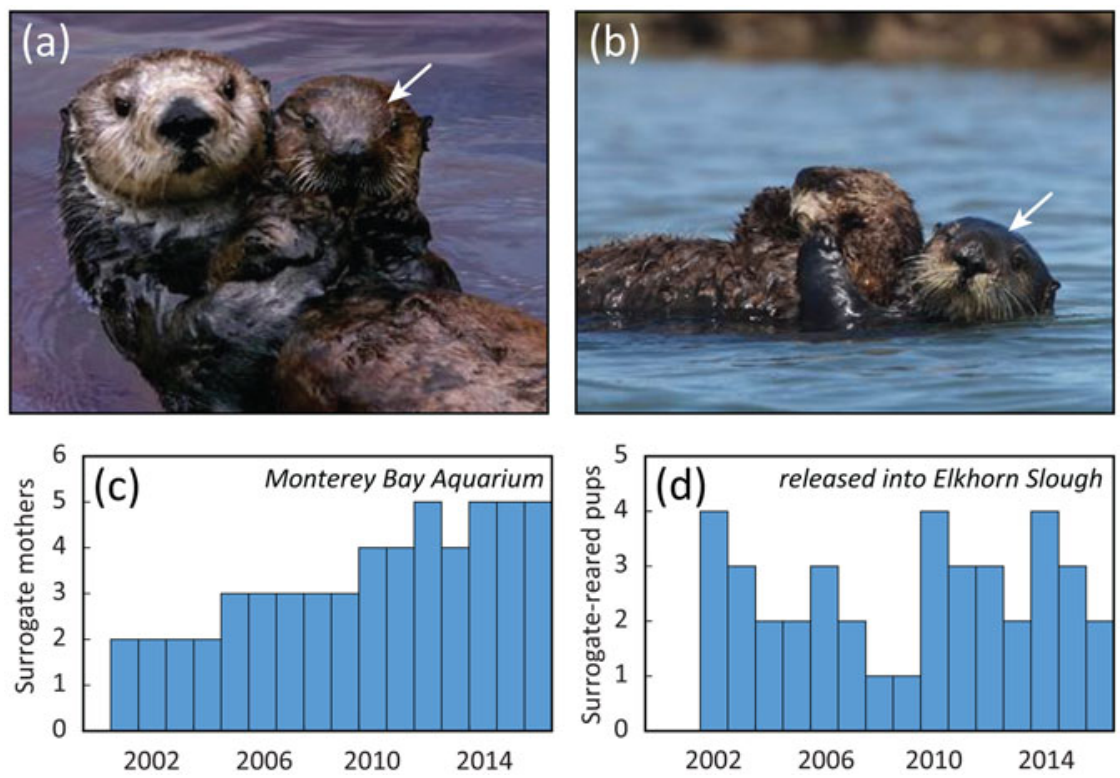

FIG. 2 Orphaned sea otter pups were reared by surrogate mothers subsequently released into the wild population where they assimilated into the population. Pup no. 327, denoted with a white arrow and shown in captivity with her surrogate mother in (a), was released into the wild and (b) began breeding and rearing her own pups. Surrogacy capacity (c) increased over time as more adult females became trained to accept orphaned pups, although rehabilitated individuals (d) varied according to logistical and environmental constraints. The facility at the Monterey Bay Aquarium is currently limited to five surrogate mothers. intervention and husbandry care. Successful rehabilitation of these pups is also dependent on a surrogacy programme, which uses non-releasable adult female sea otters as surrogate mothers to provide care for the pups (Fig 2a; Nicholson et al., 2007). Because of their young age at stranding, orphaned pups are unlikely to have established fidelity to their maternal home ranges, and may be released into novel habitats (Ralls et al., 1996). Because these juveniles learn the required survival behaviours, such as socialization and foraging skills, from surrogate sea otter mothers we propose that we can maximize survival of these juvenile animals on release while minimizing the risk of human habituation (Nicholson et al., 2007).

Here, we present the results of a long-term, experimental study aimed at examining the feasibility of a reintroduction programme for sea otters, the demographic viability of surrogate-reared juveniles, and the efficacy of their reintroduction for reestablishing sea otter populations in unoccupied habitats. We use demographic analyses to answer if surrogate-reared sea otters differ in survival and reproduction from their wild counterparts. We then use the resulting vital rate estimates to parameterize an individual-based simulation model that we use to estimate the magnitude of population growth predicted over a 15 -year period attributable to the surrogate-reared sea otters and their subsequent reproductive output. By comparing model predictions to survey-based estimates of population dynamics over this same period, we answer the question of how much the release of surrogate-reared sea otters contributed to local population recovery in Elkhorn Slough. Based on the answers to these questions, we discuss the broader management implications of our findings as they relate to stimulating sea otter range expansion in California, aiding in recovery of the subspecies and restoring ecological function to degraded ecosystems.

\section{Methods}

\section{Study area and sea otter population}

Elkhorn Slough is a $12 \mathrm{~km}^{2}$ tidal wetland adjoining Monterey Bay in central California (Fig. 1a,b) that is characterized by soft-sediment and muddy benthic substrate, intermittent eelgrass Zostera marina communities, and smaller tidal channels surrounded by pickleweed Salicornia virginica (Hughes et al., 2013). This coastal estuary was selected as the release site for this study as it already contained a small otter population (Fig. 1d), abundant prey resources, and accessible vantage points and waterways to ensure continuous monitoring of released animals. Initial recolonization of Elkhorn Slough by sea otters began in the mid 1980 os (Kvitek et al., 1988), but the population fluctuated as a result of immigration and emigration of males during the 1990s (Fig. 1d; Tinker \& Hatfield, 2016). In 2000 the first pup born in Elkhorn Slough was observed (T.R. Kiekhefer et al., unpubl. data).

We used surrogate-reared juvenile sea otters $(n=37$, Table 1) that had stranded as orphans from birth to 7 weeks of age between 2002 and 2015 (see Supplementary Material 1 for details of surrogacy methods). Our sample size was limited, in part, by the availability of surrogate mothers, but this increased as the study progressed (Fig. 2c). Comparative longitudinal data from an additional 178 wild-captured southern sea otters were available from concurrent tagging studies in Elkhorn Slough $(\mathrm{n}=26)$ and outer coast populations in Monterey and Big Sur $(n=152)$. Detailed methods and results from these field studies are presented elsewhere (Tinker et al., 2019; Tinker et al., 2016; Tinker et al., 2017). All study animals had surgically implanted VHF radio transmitters for radio-telemetry and 
TABLE 1 Summary demographic, release and survival data for surrogate-reared sea otters Enhydra lutris nereis introduced to Elkhorn Slough (Fig. 1).

\begin{tabular}{|c|c|c|c|c|c|c|}
\hline Individual & Sex & $\begin{array}{l}\text { First } \\
\text { year }^{1}\end{array}$ & $\begin{array}{l}\text { Last } \\
\text { year }^{2}\end{array}$ & $\begin{array}{l}\text { Survival } \\
\text { (days) }\end{array}$ & Fate $^{3}$ & $\begin{array}{l}\text { Last age } \\
\text { (years) }\end{array}$ \\
\hline 209 & $\mathrm{M}$ & 2002 & 2014 & 4,683 & 1 & 13 \\
\hline 217 & M & 2002 & 2012 & 3,789 & 1 & 11 \\
\hline 225 & M & 2002 & 2002 & 32 & 1 & 1 \\
\hline 228 & M & 2002 & 2002 & 30 & 1 & 1 \\
\hline 238 & M & 2003 & 2004 & 451 & 1 & 2 \\
\hline 249 & M & 2003 & 2013 & 3,726 & 1 & 11 \\
\hline 252 & M & 2003 & 2010 & 2,621 & 1 & 8 \\
\hline 269 & M & 2004 & 2010 & 2,144 & 1 & 6 \\
\hline 286 & $\mathrm{~F}$ & 2004 & 2015 & 4,088 & 0 & 12 \\
\hline 315 & M & 2005 & 2008 & 1,097 & 1 & 3 \\
\hline 327 & $\mathrm{~F}$ & 2005 & 2014 & 3,034 & 0 & 9 \\
\hline 344 & M & 2006 & 2009 & 981 & 1 & 3 \\
\hline 339 & $\mathrm{~F}$ & 2006 & 2013 & 2,618 & 0 & 8 \\
\hline 353 & $\mathrm{~F}$ & 2006 & 2007 & 243 & 1 & 1 \\
\hline 379 & $\mathrm{~F}$ & 2007 & 2013 & 2,125 & 0 & 6 \\
\hline 386 & M & 2007 & 2015 & 2,722 & 1 & 8 \\
\hline 433 & $\mathrm{~F}$ & 2008 & 2016 & 2,623 & 0 & 8 \\
\hline 451 & M & 2009 & 2015 & 1,972 & 1 & 6 \\
\hline 466 & M & 2010 & 2015 & 1,822 & 0 & 5 \\
\hline 457 & $\mathrm{~F}$ & 2010 & 2016 & 2,068 & 0 & 6 \\
\hline 473 & $\mathrm{~F}$ & 2010 & 2010 & 56 & 1 & 1 \\
\hline 475 & $\mathrm{~F}$ & 2010 & 2010 & 20 & 1 & 1 \\
\hline 501 & $\mathrm{~F}$ & 2011 & 2016 & 1,682 & 0 & 5 \\
\hline 520 & M & 2011 & 2013 & 738 & 1 & 3 \\
\hline 526 & M & 2011 & 2012 & 192 & 1 & 1 \\
\hline 518 & $\mathrm{~F}$ & 2012 & 2016 & 1,446 & 0 & 4 \\
\hline 558 & M & 2012 & 2014 & 759 & 0 & 3 \\
\hline 587 & $\mathrm{~F}$ & 2012 & 2016 & 1,178 & 0 & 4 \\
\hline 595 & $\mathrm{~F}$ & 2013 & 2013 & 38 & 1 & 1 \\
\hline 621 & $\mathrm{M}$ & 2013 & 2014 & 144 & 1 & 1 \\
\hline 641 & $\mathrm{M}$ & 2014 & 2016 & 675 & 0 & 2 \\
\hline 623 & M & 2014 & 2016 & 628 & 1 & 2 \\
\hline 653 & $\mathrm{~F}$ & 2014 & 2016 & 490 & 0 & 2 \\
\hline 657 & $\mathrm{~F}$ & 2014 & 2016 & 415 & 0 & 2 \\
\hline 671 & $\mathrm{~F}$ & 2015 & 2016 & 278 & 0 & 1 \\
\hline 673 & M & 2015 & 2015 & 52 & 0 & 1 \\
\hline 685 & $\mathrm{~F}$ & 2015 & 2016 & 140 & 0 & 1 \\
\hline
\end{tabular}

${ }^{1}$ Year individual released.

${ }^{2}$ Year individual died or was last seen alive.

${ }^{3} 1$, known mortality; o, alive at end of study or fate unknown.

coloured flipper tags for visual monitoring (Siniff \& Ralls, 1991).

\section{Release and field monitoring}

Surrogate-reared individuals were released at $0.5-1.5$ years of age, which is approximately comparable to ages at which wild pups are successfully weaned (Riedman et al., 1994). We released single individuals within the slough, with 1-4 releases annually (Fig. 2d). The first 2 weeks after each release were treated as a conditioning period, or soft-release.
During this period individuals were located and monitored daily via radio telemetry and visual observation. Individuals that were not foraging successfully (as indicated by observational data, deteriorating body condition or decreased energy level), or that exhibited symptoms of elevated stress (e.g. stereotypical pacing, vocalizing, or unproductive offshore travel) were recaptured, returned to normal health, and re-released. For the purposes of subsequent survival analyses, this 2-week point represented the time-origin of entry for each individual.

All study animals (wild-captured and released juveniles) were regularly monitored (1-5 times per week) with radio telemetry and visual observations from release until death, disappearance, or until the end of the study. Premature VHF radio failure combined with tag loss meant that the fates of some of the surrogate-reared animals were unknown (Table 1). For visually resighted females, we recorded reproductive status (whether a female had a dependent pup) and pup age (Siniff \& Ralls, 1991). Depending on the frequency of visual resights for each female, there was a small possibility of missing the births of pups that died or were abandoned soon after parturition. Success of each pup, defined as whether it survived to weaning at 6 months (Riedman et al., 1994) was also recorded whenever possible.

\section{Individual-based model}

Although the survival and partial reproductive histories of many of the surrogate-reared animals was documented, many animals had unknown fates and/or partially unknown reproductive histories, and post-weaning survival and reproductive output of their pups was entirely unknown. Thus, it was not possible to quantify the total contribution of surrogate-reared animals to population dynamics based solely on a book-keeping summation of known data. To best utilize known-fate data that were available, while accounting for uncertainty in un-observed demographic transitions of surrogate-reared animals and their descendants, we developed an individual-based model to simulate the demographic transitions of individual sea otters within Elkhorn Slough over time (DeAngelis \& Mooij, 2005). An individual-based model specifies all individual outcomes (whether each individual survives or reproduces) at discrete time steps, as opposed to simply tracking total abundance or the abundance of age-classes within the population. In the case of released juveniles, some outcomes were known and therefore deterministic in the model. For individuals in the population with partially-known or unknown survival and reproductive histories (including descendants of the surrogate-reared animals), individual fates were treated as stochastic events with probabilities defined by the age- and sex-specific survival and reproductive rates for the appropriate class of each animal. Individual-based model parameter 
estimates are summarized below; see Supplementary Material 2 for additional details.

\section{Survival rates}

Sea otter survival rates were estimated using longitudinal monitoring data described above, and a Bayesian proportional hazards model (Walsh et al., 2015) to account for the effects of age, sex, and study group, following methods previously described for sea otters (Tinker et al., 2017). Briefly, age-varying hazards for each sex were assumed to be continuous variables and estimated using nonparametric conditional auto-regressive methods (Sinha \& Dey, 1997). Group effects were categorical variables and corresponded to additional hazards relative to a reference group (Outer Coast). Age-group interactions and age-sex interactions were also included. Survival outcomes for each otter, at 1 month intervals over the duration of the study, were represented as random Bernoulli trials and comprised binomial likelihoods maximized by a Bayesian Markov chain Monte Carlo algorithm (Heisey \& Patterson, 2006). Model convergence was evaluated and confirmed by examination of Markov chain Monte Carlo trace plots and the R-hat statistic (Gelman et al., 2014). Age and sex-specific survival rates and $95 \%$ credible intervals were computed and examined graphically to determine whether there were differences in survivorship schedules between study groups.

\section{Reproductive rates}

We estimated per-capita annual birth rates (number of pups born per year per female) and weaning success rates (the probability a pup survives to weaning age of 6 months) from observational data of tagged female sea otters (wild and surrogate-reared). To estimate birth rates for each study group, we calculated the mean numbers of days between consecutive births for tagged females with three or more known consecutive pup births (and at least one pup successfully reared to weaning age). Based on previously published data (Jameson \& Johnson, 1993; Tinker et al., 2006) we assumed birth rates among females were essentially constant after 3 years of age, whereas for 2-year-olds we arbitrarily set a value of 0.25 to reflect the fact that a small proportion of 2-year-old females do reproduce.

To estimate weaning success rate, we fitted a suite of generalized linear mixed models that related putative predictor variables to the binomial response variable of known weaning outcomes for individual tagged females (following Tinker et al., 2006). As found in previous studies, the primary factor affecting weaning success was age of the mother (Tinker et al., 2013; Tinker et al., 2017); however, we also wanted to test for differences among the three study groups. We evaluated eight functional models for calculating mothers' age- and group-specific weaning success, including various combinations of age effects (linear and higher order polynomials) and group differences, as well as simpler models excluding these main effects. We then compared Akaike information criteria (AIC) values to select the best-supported model (Burnham \& Anderson, 2002).

\section{Net annual immigration rates}

The net annual immigration rates for wild males and females were unavailable from longitudinal data, and could not be estimated independently from other tagging studies. Instead, we generated maximum-likelihood estimates by comparing expected population growth using the individual-based model to observed population dynamics, while varying the net immigration of both sexes. We calculated the likelihood of obtaining the observed population counts of sea otters and pups given a set of net immigration rates for each sex and then log-transformed the data and multiplied by -1 to obtain negative log-likelihoods. This was summed across study years and we then used a global optimization algorithm to determine the values of net immigration for males and females that minimized the cumulative log-likelihood estimate. These values were then used to parameterize individual-based model simulations, described below.

\section{Individual-based model simulations}

The model simulated demographic outcomes (survival, birth rate, weaning success) for all individual sea otters within the estuary population over a sequence of 15 time steps ( 1 step $=1$ year) corresponding to the duration of the study (see Supplementary Material 3 for the pseudo-code describing a single iteration of the model) while accounting for the effects of age, sex, and study group. The model was initiated with a pool of 20 males, reflecting the observed population in Elkhorn Slough in 2002 (Tinker \& Hatfield, 2016), and then iterated with 10,000 simulations to produce a distribution of results, from which the mean and $95 \%$ credible intervals of expected population abundances over time were calculated.

The individual-based model was used to generate expected population growth trajectories under four different hypothetical scenarios, all starting from an initial population of 20 independent males, and o independent females or pups: (1) no additions of surrogate-reared juveniles, and no immigration of wild females or males; (2) no additions of surrogate-reared juveniles, but immigration of wild females and males (see Supplementary Material 2 for 
estimation of immigration rates); (3) additions of surrogatereared juveniles (according to actual release data), but no immigration of wild otters; and (4) a realistic scenario, allowing for additions of surrogate-reared juveniles (according to release data) as well as immigration of wild females and males. By comparing expected population growth under these four scenarios with observed counts, we were able to calculate the proportional contributions to population growth in Elkhorn Slough of surrogate-reared and wild otters and their progeny.

\section{Results}

We successfully released and monitored 20 males and 17 females until death, censoring because of transmitter failure and flipper tag loss (i.e. unknown fate) or end of study (Table 1). For each individual, the number of releases before passing the 2-week conditioning phase was 1-4. Despite all individuals originally stranding in open coast habitats, 16 of 20 males (80\%) and 15 of 17 females (88\%) remained in Elkhorn Slough after release.

\section{Survival rates}

Longitudinal data on survival were available for a total of 215 tagged sea otters from three overlapping studies (Supplementary Table 1). We found no strong differences in hazard ratios between surrogate-reared and wild-captured otters in Elkhorn Slough or along the open coast (Supplementary Fig. 1). Hazards associated with age and sex differences varied among all study groups, resulting in inverted- $U$ shape survival curves that are typical for sea otters and other large mammals (Fig. 3; Tinker et al., 2017). Because there were no significant differences in survival among the three study groups overall, we used age- and sex-specific survival rates associated with wild-captured Elkhorn Slough otters to parameterize the individual-based model.

\section{Reproductive rates}

A total of 72 females were included in the analysis of per capita birth rates, including 62 otters from outer coast populations, four wild otters captured in Elkhorn Slough, and six surrogate-reared otters. Three additional surrogate-reared females who were known to have reproduced were excluded from the analysis either because they were too young to have given birth to a minimum of three pups or because consecutive births with at least one successfully weaned pup had not been recorded. As in previous studies of reproduction in sea otters (Riedman et al., 1994; Tinker et al., 2006, 2019), we found that birth rates were consistent across study groups, with mean values of $0.943^{-1.032}$ and overlapping $95 \%$ $\therefore$ Elk. Slough (wild) $>$ Outer coast (wild) $>$ Elk. Slough (surrogate-reared)

(a)
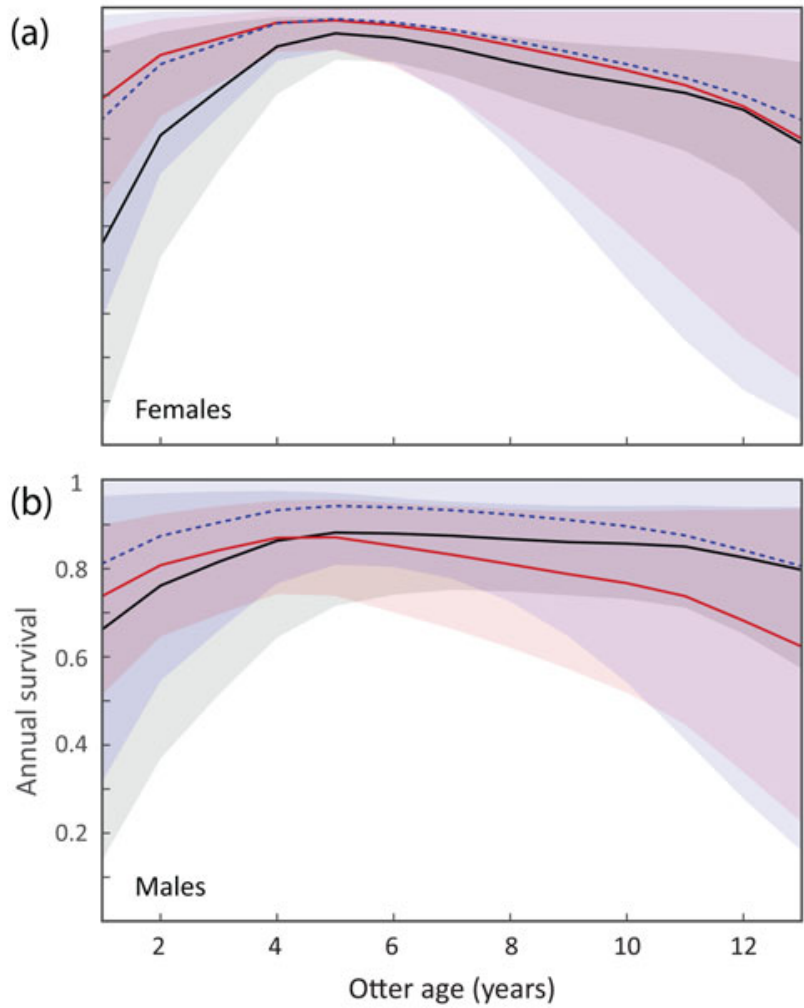

FIg. 3 Median age-specific annual survival rates for (a) females and (b) males were virtually indistinguishable between surrogate-reared and wild sea otters. The same broad pattern, with survival increasing to a plateau from juvenile to adult stages, and declining with senescence, was consistent for both sexes and among the three study groups. This pattern was also consistent in two regions: Elkhorn Slough, where surrogatereared otters were released, and the open ocean region surrounding the Monterey Peninsula (outer coast). Sample sizes for both females and males were limited for older otters, and explained in part the large confidence bands (shaded areas) around the median values. Y-axis scale and labels are constrained in both panels.

credible intervals (Table 2). As a result, the overall mean birth rate across study groups (o.998) was used to parameterize the model.

Weaning success rates were analysed using data from a total of 340 pup dependencies with known outcomes (success or failure) for 132 tagged females. Based on AIC comparison, the best supported model included both linear and non-linear effects of mother's age, but no effect of study group (Table 3). The best-fit generalized linear mixed model showed an increasing probability of weaning success with mother's age, reaching an asymptote by 6 years and then declining slightly for older females (Supplementary Fig. 2). Therefore, we used the mean agespecific values of weaning success for all study groups combined to parameterize the individual-based model. 
TABLE 2 Summary of annual mean birth rate estimates for female sea otters from three study groups, based on longitudinal records for tagged females having three or more consecutive pup births.

\begin{tabular}{lllr}
\hline & $\begin{array}{l}\text { Mean birth } \\
\text { rate } \pm \text { SD }\end{array}$ & $\begin{array}{l}\text { 95\% Confidence } \\
\text { interval }\end{array}$ & $\mathrm{n}$ \\
\hline Outer coast & $1.008 \pm 0.113$ & $0.966-1.062$ & 62 \\
Elkhorn slough wild & $0.943 \pm 0.137$ & $0.725-1.161$ & 4 \\
Elkhorn slough released & $1.032 \pm 0.092$ & $0.959-1.106$ & 6 \\
Overall mean & $0.998 \pm 0.114$ & & \\
\hline
\end{tabular}

\section{Immigration rates}

The maximum-likelihood analysis indicated relatively low annual net rates of immigration for males and females, with the value for females $\left(\lambda_{F}=0.6\right.$ otters per year) less than one-third that for males $\left(\lambda_{M}=2.5\right.$ otters per year; Supplementary Fig. 3). The individual-based model treated immigration as a stochastic Poisson process, with mean values corresponding to the maximum-likelihood estimates.

\section{Individual-based model simulations}

Model projections of population growth in Elkhorn Slough during 2002-2016 differed greatly depending on assumptions about introductions of surrogate-reared otters and net immigration of wild otters. The first scenario (no additions of surrogate-reared otters and no immigration of wild females and males) showed a steady decline in population abundance as the resident population of males died out and were not replaced (Fig. 4a). The second scenario (allowing for immigration of wild otters, but no addition of surrogate-reared juveniles) showed a slow exponential increase of both adults and pups, although the rate of increase was less than half that observed in the actual survey data (Fig. 4b). The third scenario (allowing for the additions of surrogate-reared juveniles and subsequent reproductive output, but no immigration of wild otters) also showed an exponential rate of increase in adults and pups, with a rate of increase higher than scenario 2, but still lower than that observed in actual survey data (Fig. 4c). The fourth scenario (allowing for additions of surrogate-reared juveniles and immigration of wild females and males) showed rapid exponential growth of both adults and pups, closely matching the survey data (Fig. 4d).

Combining these model results, the proportionate contributions of surrogate-reared otters and their reproductive output to population growth in Elkhorn Slough varied among years, but accounted for c. $55 \%$ of overall observed population growth, and $64 \%$ of pup production over the study period (Fig. 5, Supplementary Table 2).

\section{Discussion}

This study highlights the potential role that reintroduced, surrogate-reared juvenile animals can play in enhancing population growth in new habitats. The surrogacy methods we used allowed naïve juveniles to be successfully returned to the wild with survival (Fig. 3) and reproductive rates (Table 2) similar to the native population. We also show that releasing a small number of surrogate-reared juveniles annually had substantial impacts on population growth in Elkhorn Slough (Fig. 4c). Our model results indicate that surrogate-reared otters and their descendants represented over half of the local population growth that occurred during the study period (Fig. 5) and that this growth cannot be explained without their contributions (Fig. 4). This rapid population growth in Elkhorn Slough also coincided with increased eelgrass cover and improved ecosystem health in the Elkhorn Slough as a result of the ecosystem services sea otters provide (Hughes et al., 2013).

The successful establishment of relocated sea otters observed in this study is in contrast to previous sea otter translocation efforts in California. In the 1980s, managers attempted to establish a refuge population of sea otters in the unpopulated and geographically-isolated Channel Islands, to ensure population persistence in the event of a

TABLE 3 Comparison of alternative functional form for a generalized linear mixed model fitted to data on weaning success for tagged sea otters in Elkhorn Slough and the outer coast (Fig. 1).

\begin{tabular}{|c|c|c|c|}
\hline Model form ${ }^{1}$ & $\mathrm{AIC}^{2}$ & Log-likelihood & Deviance \\
\hline Outcome $\sim 1$ & 449.6465 & -222.823 & 445.6465 \\
\hline Outcome $\sim 1+$ AgeM & 451.5395 & -222.770 & 445.5395 \\
\hline Outcome $\sim 1+$ AgeM + AgeM $^{2}$ & 453.4010 & -222.701 & 445.4010 \\
\hline Outcome $\sim 1+$ AgeM + AgeM $^{2}+$ AgeM $^{3}$ & 447.9023 & -218.951 & 437.9023 \\
\hline Outcome $\sim 1+$ Group & 450.9485 & -222.474 & 444.9485 \\
\hline Outcome $\sim 1+$ AgeM + Group & 452.9313 & -222.466 & 444.9313 \\
\hline Outcome $\sim 1+$ AgeM + AgeM $^{2}+$ Group & 454.8609 & -222.430 & 444.8609 \\
\hline Outcome $\sim 1+$ AgeM + AgeM $^{2}+$ AgeM $^{3}+$ Group & 449.7438 & -218.872 & 437.7438 \\
\hline
\end{tabular}

${ }^{1}$ Fixed effects evaluated include linear and higher order terms for mother's age, and the categorical effect of study group (outer coast vs Elkhorn Slough wild vs surrogate-reared). Individual tagged females were included as a random effect in all models.

${ }^{2} \mathrm{AIC}$ statistics are shown for each model, with the lowest AIC value indicating the best-supported model (bold typeface). 

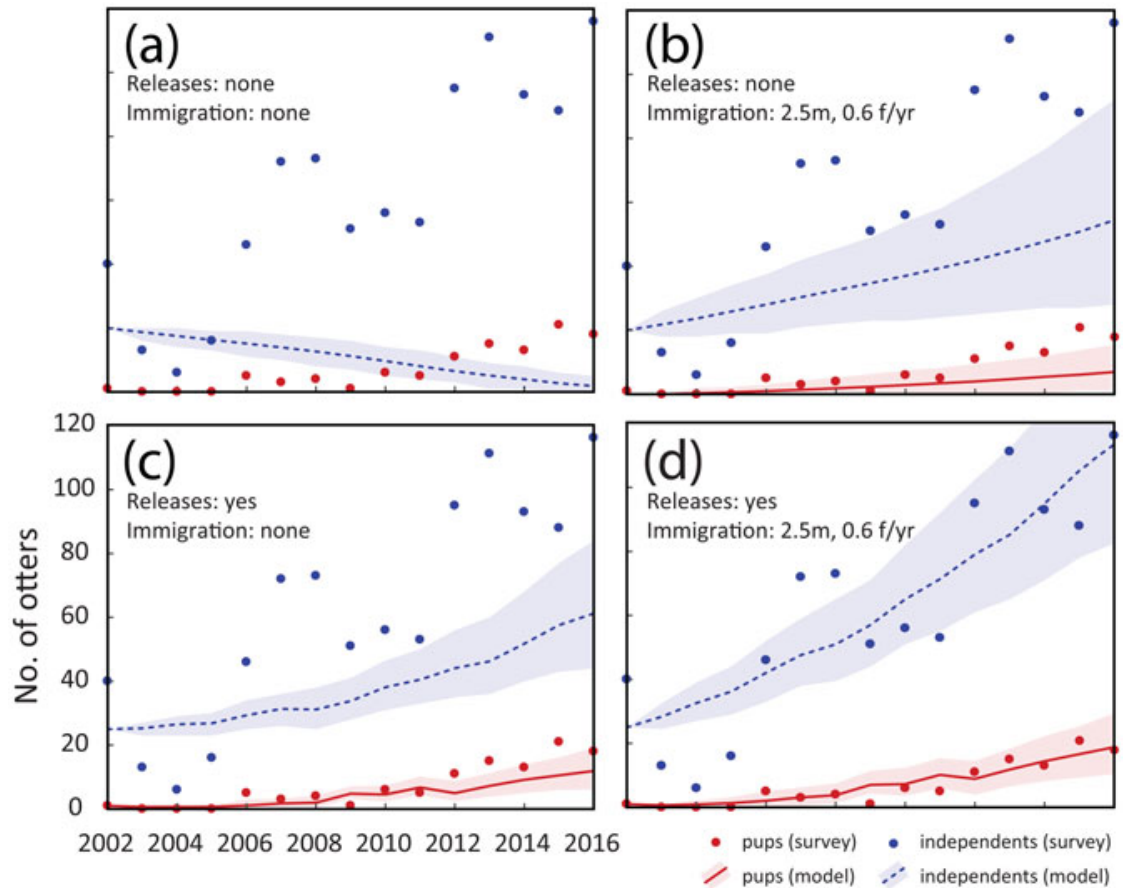

FIG. 4 Sea otter population trends in Elkhorn Slough during 2002-2016 were largely attributed to the release of surrogate-reared juveniles and their subsequent reproductive output but were also influenced by natural immigration. Population reconstructions that (a) excluded natural immigration and surrogate-releases, (b) excluded releases but included immigration, and (c) included releases but excluded immigration did not predict the observed numbers of pups or older otters (independents) as well as the model that included both (d). The highest-ranked population model $(\mathrm{d})$ incorporated releases of surrogate-reared otters as well as natural immigration of 2.5 males (m) and 0.6 females (f) per year. Y-axis scale and labels are constrained in all panels. catastrophic oil spill (Rathbun et al., 200o). Juvenile and adult sea otters were captured from the mainland population and translocated to the remote San Nicolas Island. Although there was abundant prey at the new location, most (up to 90\%) of the otters either traversed open-ocean distances of $>100 \mathrm{~km}$ to return to their previous habitat, or

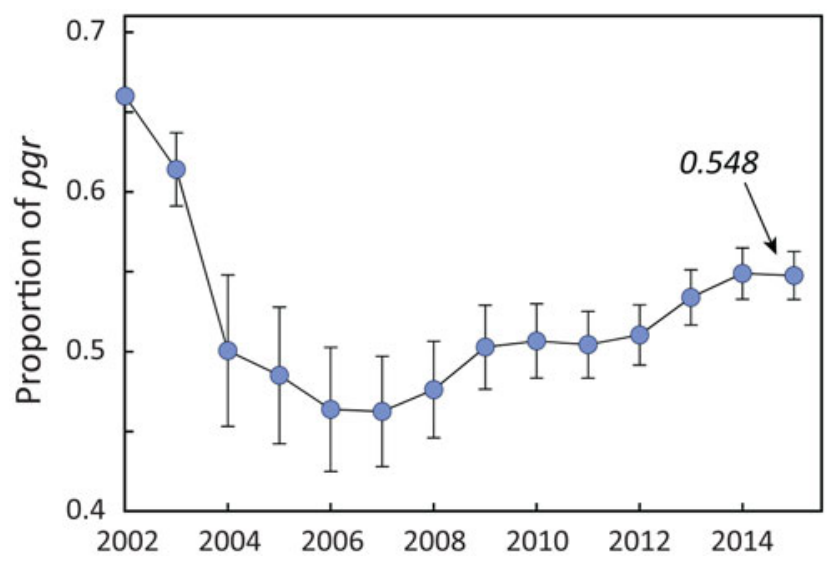

FIG. 5 Surrogate-reared otters and their descendants represented over half of the population growth observed in Elkhorn Slough during the study period. The contribution of surrogate-reared otters to the median $( \pm \mathrm{SE}$ ) population growth rate started high, because initial additions of released individuals in 2002 had a greater relative impact on the small resident population. Proportion of population growth rate declined during 20022006 as the resident population grew as a result of natural immigration in addition to released individuals, but then gradually increased during $2007-2016$ as pup production by surrogate-reared females also contributed to population growth. disappeared entirely (Carswell, 2008). Our study is different from this example in several important ways. Firstly, our study location was adjacent to the geographical center of the sea otter range, on the California mainland (Fig. 1). Despite this proximity, however, the habitat was initially relatively unoccupied by otters, with only a small base of non-territorial males. Secondly, rather than working in a relatively pristine kelp forest ecosystem, such as San Nicolas Island, our site was a highly-impacted, shallow, coastal estuary. Thirdly, instead of seeding the habitat with wild otters, we released juveniles that were ecologically naïve, who were surrogate-reared in captivity after stranding (Fig. 2). These differences are important to consider for any future reintroduction efforts, and the role of established occupancy and habitat type on reintroduction success warrants additional study. Our findings suggest that the release of ecologically naïve juveniles was a viable alternative to capturing and relocating wild sea otters.

The comparable survival rates between surrogate-reared animals and their wild counterparts (Fig. 3) can be largely attributed to the surrogacy rearing methods and the softrelease protocol, which gave naïve juveniles the highest probability of successfully assimilating with the wild population. The use of surrogate sea otter mothers, as well as housing juveniles with other conspecifics, provided pups with an appropriate social context for developing important survival skills, such as foraging and tool-use, while minimizing the risk of human habituation (Nicholson et al., 2007). Surrogacy has been previously implemented in isolated cases to rear orphaned young that remain in captivity (e.g. Rogers, 1985; Ridgway et al., 1995; Gaspar et al., 2000; 
Hoff et al., 2005). Our study is the first case in which surrogacy has been used to bolster a wild population. As seen in other rehabilitation programmes, soft-releases may also improve survival and reproductive performance (Mitchell et al., 2011; Adimey et al., 2016). Most juveniles required at least one recapture and temporary return to captivity before successfully transitioning to the wild. This high degree of monitoring during the initial 2-week release period increased individual survival and assimilation into the wild population.

The birth and weaning of pups were key indicators that surrogate-reared females had successfully reentered the wild population and contributed to additional population growth. Despite similar reproductive and weaning success rates among all study populations, surrogate-reared females contributed a greater proportion (64\%) of the pup production than wild Elkhorn Slough females (Supplementary Table 2). Prior to the initiation of our study, Elkhorn Slough was predominantly occupied by a small group of transient males. Given this discrete population and low net immigration of females, the addition of surrogate-reared females apparently had disproportionate effects on initial reproduction.

We measured the impact of reintroduced individuals on a small population, which is vital to determining the efficacy of a reintroduction programme, through long-term monitoring and individual-based model simulations. Overall, the introduction of surrogate-reared juveniles contributed to more than half of the observed population growth in Elkhorn Slough (Fig. 5). There are at least three reasons for their substantial impacts. Firstly, surrogate-reared females appear to have been among the first to produce pups in Elkhorn Slough; thus, it is possible that these individuals acted as pioneers that triggered a shift in the Slough population from a seasonally abundant male area to a resident mixed-sex reproductive population. This pattern has also been observed at the periphery of sea otter ranges (Lafferty \& Tinker, 2014). Secondly, almost $90 \%$ of surrogate-reared females and approximately $80 \%$ of males remained in Elkhorn Slough after release. The use of juvenile individuals without established ecological memory probably provided greater capacity to reintroduce sea otters into unfamiliar habitat within a historically-occupied region. Thirdly, at the start of the study Elkhorn Slough was probably primed for rapid sea otter population growth, with abundant prey, sheltered habitats that acted as nurseries for mothers and pups, and a small but established population that provided conspecifics from which juveniles could learn. Similar patterns of population segregation, survival and reproduction were observed in Clam Lagoon, a small estuary on Adak Island, Alaska (Tinker \& Estes, 1996), indicating successful recolonization of estuaries is a repeatable endeavour.

The success of our study is promising and provides strong support for the use of surrogacy-based rehabilitation and reintroduction methods as an alternative to traditional translocations. However, the degree to which released surrogate-reared sea otters would affect regions without an existing population base is unknown. Here, we demonstrate how captive surrogate mothers raised wild-born, orphaned juveniles with the necessary skills to survive in the wild, allowing their successful release into novel habitats. This has been important for bolstering local populations within the existing sea otter range and has subsequently helped restore those ecosystems. Such methods may become increasingly relevant at and beyond the range edges, where the emergence of complex ecosystem changes (Moxley et al., 2019) is a challenge for the conservation of sea otters and fluctuating ecosystems.

Acknowledgements This research was supported by generous contributions to the Monterey Bay Aquarium. C. DeAngelo, S. Hazan, D. Cori, M. Young, E. Lenihan, J. Hymer, G. Bentall, J. Stewart and numerous staff and volunteers provided animal care, field monitoring and logistical support throughout the 15 years of the study. The Marine Mammal Center and California Department of Fish and Wildlife, particularly M. Harris, assisted with sea otter stranding response. D. Casper and H. Harris contributed veterinary care and expertise. B. Van Wagenen of Ecoscan Resource Data, R. Eby, and other volunteers from the Elkhorn Slough National Estuarine Research Reserve located wayward otters. L. Carswell assisted with federal permits. The Moss Landing Harbor District and Elkhorn Slough National Estuarine Research Reserve authorized access and field operations. J. Yee and two anonymous reviewers provided critiques of the text.

Author contributions Study design: KM, AJ, TT, KV; design of methods and collection of field monitoring data: KM, MS, TN, JF; provision of veterinary care: $\mathrm{MM}$; model design and data analysis: TT; figure production: TT, KV; writing: KM, JF, TT, KV; revisions: all authors.

\section{Conflicts of Interest None.}

Ethical Standards All research activities were authorized by the U.S. Fish and Wildlife Service. Any use of trade, firm, or product names is for descriptive purposes only and does not imply endorsement by the U.S. Government. The scope of the research outlined in this study and all protocols for use of live southern sea otters were approved by the Institutional Animal Care and Use Committee of the Monterey Bay Aquarium. Animal housing facilities complied with U.S. Department of Agriculture regulations governing welfare of marine mammals, and met Association of Zoos and Aquariums accreditation standards. This research abided by the Oryx guidelines on ethical standards.

\section{References}

Adimey, N.M., Ross, M., Hall, M., Reid, J.P., Barlas, M.E., Keith Diagne, L.W. \& Bonde, R.K. (2016) Twenty-six years of postrelease monitoring of Florida manatees (Trichechus manatus latirostris): evaluation of a cooperative rehabilitation program. Aquatic Mammals, 42, 376-391.

Batson, W.G., Gordon, I.J., Fletcher, D.B. \& Manning, A.D. (2015) Translocation tactics: a framework to support the IUCN Guidelines for wildlife translocations and improve the quality of applied methods. Journal of Applied Ecology, 52, 1598-1607. 
Berger, J., Stacey, P.B., Bellis, L. \& Johnson, M.P. (2001) A mammalian predator-prey imbalance: grizzly bear and wolf extinction affect avian neotropical migrants. Ecological Applications, 11, 947-960.

Beschta, R.L. \& Ripple, W.J. (2009) Large predators and trophic cascades in terrestrial ecosystems of the western United States. Biological Conservation, 142, 2401-2414.

Burnham, K.P. \& Anderson, D.R. (2002) Model Selection and Inference: a Practical Information-Theoretic Approach. Springer-Verlag, New York, USA.

Carswell, L.P. (2008) How do Behavior and Demography Determine the Success of Carnivore Reintroductions? A Case Study of Southern Sea Otters, Enhydra Lutris nereis, Translocated to San Nicolas Island. University of California, Santa Cruz, USA.

Carswell, L.P., Speckman, S.G. \& Gill, V.A. (2015) Shellfish fishery conflicts and perceptions of sea otters in California and Alaska. In Sea Otter Conservation (eds S.E. Larson, J.L. Bodkin \& G.R. VanBlaricom), pp. 333-368. Academic Press, Cambridge, USA.

DeAngelis, D.L. \& MooIJ, W.M. (2005) Individual-based modeling of ecological and evolutionary processes. Annual Review of Ecology, Evolution, and Systematics, 36, 147-168.

Estes, J.A. \& Duggins, D.O. (1995) Sea otters and kelp forests in Alaska: generality and variation in a community ecological paradigm. Ecological Monographs, 65, 75-100.

Estes, J.A. \& Palmisano, J.F. (1974) Sea otters: their role in structuring nearshore communities. Science, 185, 1058-1060.

Estes, J.A., Terborgh, J., Brashares, J.S., Power, M.E., Berger, J., Bond, W.J. et al. (2011) Trophic downgrading of planet Earth. Science, 333, 301-306.

Fischer, J. \& Lindenmayer, D.B. (2000) An assessment of the published results of animal relocations. Biological Conservation, 96, 1-11.

Gaspar, C., Lenzi, R., Reddy, M. \& Sweeney, J. (2000) Spontaneous lactation by an adult Tursiops truncatus in response to a stranded Steno bredanensis calf. Marine Mammal Science, 16, 653-658.

Gelman, A., Carlin, J.B., Stern, H.S., Dunson, D.B., Vehtari, A. \& Rubin, D.B. (2014) Bayesian Data Analysis, CRC Press, Boca Raton, USA.

Gilmartin, W.G., Sloan, A.C., Harting, A.L., Johanos, T.C., Baker, J.D., Breese, M. \& Ragen, T.J. (2011) Rehabilitation and relocation of young Hawaiian monk seals (Monachus schauinslandi). Aquatic Mammals, 37, 332-341.

Griffith, B., Scott, J.M., Carpenter, J.W. \& Reed, C. (1989) Translocation as a species conservation tool: status and strategy. Science, 245, 477-480.

Guy, A.J., Curnoe, D. \& Banks, P.B. (2013) A survey of current mammal rehabilitation and release practices. Biodiversity and Conservation, 22, 825-837.

Heisey, D.M. \& Patterson, B.R. (2006) A review of methods to estimate cause-specific mortality in presence of competing risks. Journal of Wildlife Management, 70, 1544-1555.

Hoff, M., Tarou, L., Horton, C., Mayo, L. \& Maple, T. (2005) Notes on the introduction of an 11 week-old infant Western lowland gorilla Gorilla gorilla gorilla to a non-lactating surrogate mother at Zoo Atlanta. International Zoo Yearbook, 39, 191-198.

Hughes, B.B., Eby, R., Van Dyke, E., Tinker, M.T., Marks, C.I., Johnson, K.S. \& WAsson, K. (2013) Recovery of a top predator mediates negative eutrophic effects on seagrass. Proceedings of the National Academy of Sciences, 201302805.

JAMESON, R.J. \& Johnson, A.M. (1993) Reproductive characteristics of female sea otters. Marine Mammal Science, 9, 156-167.

Kenyon, K.W. (1969) The sea otter in the eastern Pacific Ocean. North American Fauna, 68, 1-352.
Kleiman, D., Price, M.S. \& Beck, B. (1994) Criteria for reintroductions. In Creative Conservation (eds A. Feistner, G.M. Mace \& P.J.S. Olney), pp. 287-303. Springer, London, UK.

Kvitek, R., Fukayama, A., Anderson, B. \& Grimm, B. (1988) Sea otter foraging on deep-burrowing bivalves in a California coastal lagoon. Marine Biology, 98, 157-167.

Lafferty, K.D. \& Tinker, M.T. (2014) Sea otters are recolonizing southern California in fits and starts. Ecosphere (Washington, D.C.), $5,1-11$.

Laidre, K.L., Jameson, R.J. \& Demaster, D.P. (2001) An estimation of carrying capacity for sea otters along the California coast. Marine Mammal Science, 17, 294-309.

Loomis, J. (2006) Estimating recreation and existence values of sea otter expansion in California using benefit transfer. Coastal Management, 34, 387-404.

Massei, G., Quy, R.J., Gurney, J. \& Cowan, D.P. (2010) Can translocations be used to mitigate human-wildlife conflicts? Wildlife Research, 37, 428-439.

Miller, B., Ralls, K., Reading, R.P., Scott, J.M. \& Estes, J. (1999) Biological and technical considerations of carnivore translocation: a review. Animal Conservation, 2, 59-68.

Mitchell, A.M., Wellicome, T.I., Brodie, D. \& Cheng, K.M. (2011) Captive-reared burrowing owls show higher site-affinity, survival, and reproductive performance when reintroduced using a soft-release. Biological Conservation, 144, 1382-1391.

Moxley, J., Nicholson, T.E., Van Houtan, K.S. \& Jorgensen, S. (2019) Non-trophic impacts from white sharks complicate population recovery for sea otters. Ecology and Evolution, 9, 6378-6388.

Nicholson, T.E., Mayer, K.A., Staedler, M.M. \& Johnson, A.B. (2007) Effects of rearing methods on survival of released free-ranging juvenile southern sea otters. Biological Conservation, 138, 313-320.

Nicholson, T.E., Mayer, K.A., Staedler, M.M., Fujil, J.A., Murray, M.J., Johnson, A.B. et al. (2018) Gaps in kelp cover may threaten the recovery of California sea otters. Ecography, 41, $1751-1762$.

Norris, T. (2011) Evaluation of the captive care and post-release behavior and survival of seven juvenile female Hawaiian monk seals (Monachus schauinslandi). Aquatic Mammals, 37, 342-353.

Pimm, S.L., Dollar, L. \& BAss, O.L. (2006) The genetic rescue of the Florida panther. Animal Conservation, 9, 115-122.

Ralls, K., Eagle, T.C. \& Siniff, D. (1996) Movement and spatial use patterns of California sea otters. Canadian Journal of Zoology, 74, 1841-1849.

Rathbun, G.B., Hatfield, B.B. \& Murphey, T.G. (2000) Status of translocated sea otters at San Nicolas Island, California. The Southwestern Naturalist, 45, 322-328.

Ridghay, S., Kamolnick, T., Reddy, M., Curry, C. \& Tarpley, R.J. (1995) Orphan-induced lactation in Tursiops and analysis of collected milk. Marine Mammal Science, 11, 172-182.

Riedman, M.L., Estes, J.A., Staedler, M.M., Giles, A.A. \& CARLSON, D.R. (1994) Breeding patterns and reproductive success of California sea otters. The Journal of Wildlife Management, 58 , 391-399.

Rogers, L.L. (1985) Aiding the wild survival of orphaned bear cubs. Wildife Rehabilitation, 4, 104-111.

Ruth, T.K., Logan, K.A., Sweanor, L.L., Hornocker, M.G. \& Temple, L.J. (1998) Evaluating cougar translocation in New Mexico. The Journal of Wildlife Management, 62, 1264-1275.

Sarrazin, F. \& Barbault, R. (1996) Reintroduction: challenges and lessons for basic ecology. Trends in Ecology and Evolution, 11, $474-478$. 
Seddon, P.J., Armstrong, D.P. \& Maloney, R.F. (2007) Developing the science of reintroduction biology. Conservation Biology, 21, 303-312.

Seddon, P.J., Griffiths, C.J., Soorae, P.S. \& Armstrong, D.P. (2014) Reversing defaunation: restoring species in a changing world. Science, 345, 406-412.

Sinha, D. \& Dey, D.K. (1997) Semiparametric Bayesian analysis of survival data. Journal of the American Statistical Association, 92, 1195-1212.

SinifF, D.B. \& Ralls, K. (1991) Reproduction, survival and tag loss in California sea otters. Marine Mammal Science, 7, 211-299.

Tinker, M.T. \& Hatfield, B.B. (2016) California Sea Otter (Enhydra lutris nereis) Census Results, Spring 2016. U.S. Geological Survey, USA.

Tinker, T. \& Estes, J. (1996) The population ecology of sea otters at Adak Island, Alaska. Final Report to the Navy, Contract.

Tinker, M.T., Doak, D.F., Estes, J.A., Hatfield, B.B., Staedler, M.M. \& BODKIN, J.L. (2006) Incorporating diverse data and realistic complexity into demographic estimation procedures for sea otters. Ecological Applications, 16, 2293-2312.

Tinker, M.T., Bentall, G. \& Estes, J.A. (2008) Food limitation leads to behavioral diversification and dietary specialization in sea otters. Proceedings of the National Academy of Sciences of the United States of America, 105, 560-565.
Tinker, M.T., Hatfield, B.B., Harris, M.D. \& Ames, J.A. (2016) Dramatic increase in sea otter mortality from white sharks in California. Marine Mammal Science, 32, 309-326.

Tinker, M.T., Jessup, D., Staedler, M., Murray, M., Miller, M., Burgess, T. et al. (2019) Southern Sea Otter (Enhydra lutris nereis) Population Biology at Big Sur and Monterey, CaliforniaInvestigating the Consequences of Resource Abundance and Anthropogenic Stressors for Sea Otter Recovery. U.S. Geological Survey Open-File Report 2019-1022. Sacramento, USA.

Tinker, M.T., Tomoleoni, J., LaRoche, N., Bowen, L., Miles, A.K., Murray, M. et al. (2017) Southern Sea Otter Range Expansion and Habitat Use in the Santa Barbara Channel, California. U.S. Geological Survey Open-File Report 2017-1001. Sacramento, USA.

U.S. Fish And Wildlife Service (2003) Final revised recovery plan for the southern sea otter (Enhydra lutris nereis). Portland, USA.

Van Houtan, K.S., Halley, J.M., van Aarde, R.J. \& Pimm, S.L. (2009) Achieving success with small, translocated mammal populations. Conservation Letters, 2, 254-262.

Van Houtan, K.S., Hargrove, S.K. \& Balazs, G.H. (2010) Land use, macroalgae, and a tumor-forming disease in marine turtles. PLOS ONE, 5, e1290o.

Walsh, D.P., Dreitz, V.J. \& Heisey, D.M. (2015) Integrated survival analysis using an event-time approach in a Bayesian framework. Ecology and Evolution, 5, 769-780. 